\title{
EFFECT OF ADDING ANTIBIOTIC TO ZINC OXIDE EUGENOL-BASED SEALER UPON THE APICAL SEAL (IN VITRO STUDY)
}

\author{
Mohamed A Mohammedeen*
}

\begin{abstract}
Objectives: The aim of this study was to evaluate the apical leakage of zinc oxide eugenol-based endodontic sealer with and without the addition of amoxicillin. Materials and methods: Thirty, single-rooted, anterior teeth were flattened to create a standardized length of $14 \pm 1 \mathrm{~mm}$. The canals were prepared using crown-down technique with ProTaper Universal rotary system. The roots were divided into two experimental groups $(n=10)$ according to the sealer used and two control groups ( $n=5)$. Group 1: obturated using gutta percha and zinc oxide and eugenol-based sealer, Group 2: obturated using gutta percha and zinc oxide and eugenol-based sealer with amoxicillin antibiotic. Negative control group: ( $n=5)$.Positive control group: ( $n=5)$. Results: there was no statistically significant difference between sealer and sealer with antibiotic groups for apical leakage results. Conclusion: Adding amoxicillin to zinc oxide and eugenol-based sealer did not affect the sealing ability of the sealer.
\end{abstract}

KEYWORDS: Zinc oxide and eugenol, Apical seal, Antibiotics, Amoxicillin.

\section{INTRODUCTION}

Introduction: The absence of microorganisms in the root canal system is a fundamental factor for the prognosis of endodontic treatment. Prognosis is the forecast of the course of a disease. To achieve this goal, the filling material should allow sealing of the root canal at both the root apex and the crown. Sealers are used to attain an impervious seal between the core material and root canal walls. They are usually grouped according to their basic component, e.g. zinc oxide and eugenol, calcium hydroxide, resin, glass ionomer, iodoform or silicon. Ideally, these materials should seal the canal laterally and apically, have good adaptation to root canal dentin and penetrate deeply into the dentinal tubules. In addition, sealers should demonstrate adhesive properties to dentin, decreasing the chance of endodontic treatment failure.

Increased adhesive properties to dentin may lead to greater strength of the restored tooth, which may provide greater resistance to tooth fracture and clinical longevity of an endodontically treated tooth. Adding antibiotics to a sealer can enhance their antimicrobial effect and could provide important advantages in reducing the critical concentration of microbes necessary for a host response.

Very few studies in the literature evaluated the physical properties of endodontic sealer after adding antimicrobial agent (amoxicillin) to it; this is thus, the purpose of that present study.

The Aim of the Study: The aim of this study was to evaluate the apical leakage of zinc oxide eugenol-based endodontic sealer with and without the addition of amoxicillin.

Materials and Methods: Thirty, single-rooted, anterior teeth were flattened to create a standardized length of $14 \pm 1 \mathrm{~mm}$. The canals were prepared using crown-down technique with ProTaper Universal rotary system. At each instrument change, $2 \mathrm{ml}$ of

* B.D.S (2007) O6U, M.D.Sc (2015) Cairo Universiy 
$2.5 \% \mathrm{NaOCl}$ irration was used. The roots were divided into two experimental groups $(n=10)$ according to the sealer used and two control groups $(n=5)$. Group 1: obturated using gutta percha and zinc oxide and eugenol-based sealer, Group 2: obturated using gutta percha and zinc oxide and eugenol-based sealer with amoxicillin antibiotic. Negative control group:( $n=5)$. Positive control group:( $n=5)$, Sealing ability of the tested endodontic sealers was measured using the dye extraction method. The external surface of all roots of the experimental and negative control groups was covered by two layers of clear nail varnish except at the apical root end; the whole external surface of all the roots of negative control group was completely covered by clear nail varnish. The apices of all specimens were dipped in eppendorf tubes containing a $2 \%$ buffered methylene blue dye solution for 1 week. After removal from the dye, all specimens were rinsed under tap water for $30 \mathrm{~min}$ and the varnish was removed. Each Specimen was then stored in a glass vial containing nitric acid for 3 days.

\section{RESULTS}

The mean and standard deviation values of the optical density (OD) of the experimental groups and control groups, in a descending order, were as follows (Fig.1 and Table 1):

The positive control group $(1.499 \pm 0.21)$, the sealer without antibiotic $(0.481 \pm 0.09)$, sealer with antibiotic $(0.433 \pm 0.11)$ and the negative control group $(0.275 \pm 0.04)$.

There was statistically significant difference among the four groups $(\mathrm{p}=0.001)$. The positive control group showed the statistically significantly highest OD. Both sealer preparations showed statistically significantly lower mean OD. The negative control showed the statistically significantly lowest mean OD. There were no statistically significant difference, however, between the sealer with or without antibiotic $(\mathrm{p}=0.42)$.

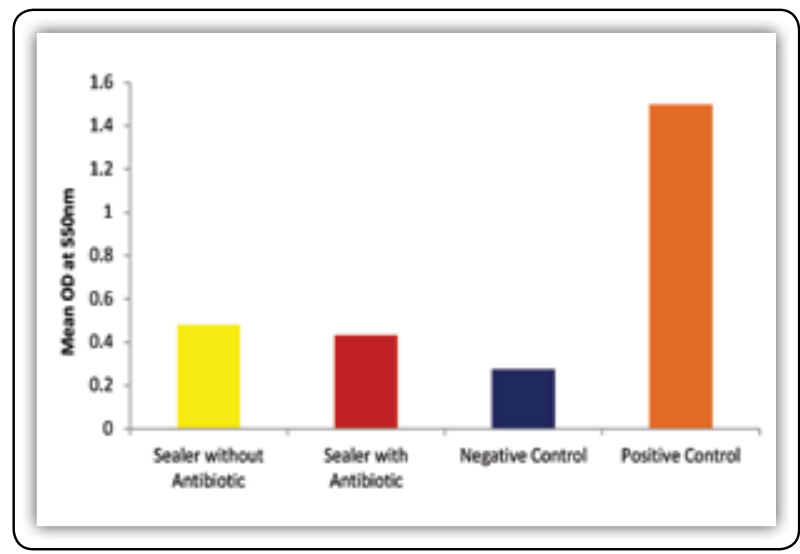

FIG (1) Bar chart representing optical density of experimental and control groups.

TABLE (1): The mean, standard deviation (SD) values for optical density of experimental and control groups

\begin{tabular}{|c|c|c|c|c|}
\hline $\begin{array}{c}\text { Sealer } \\
\text { without } \\
\begin{array}{c}\text { Antibiotic } \\
\text { Mean } \pm \text { SD }\end{array}\end{array}$ & $\begin{array}{c}\text { Sealer } \\
\text { with } \\
\text { Antibiotic } \\
\text { Mean } \pm \text { SD }\end{array}$ & $\begin{array}{c}\text { Negative } \\
\text { control } \\
\text { Mean } \pm \text { SD }\end{array}$ & $\begin{array}{c}\text { Positive } \\
\text { control } \\
\text { Mean } \pm \text { SD }\end{array}$ & $\boldsymbol{P}$-value \\
\hline $\begin{array}{c}0.481 \\
\pm 0.09^{\mathrm{b}}\end{array}$ & $\begin{array}{c}0.433 \\
\pm 0.11^{\mathrm{b}}\end{array}$ & $\begin{array}{c}0.275 \\
\pm 0.05^{\mathrm{c}}\end{array}$ & $\begin{array}{c}1.499 \\
\pm 0.21^{\mathrm{a}}\end{array}$ & $0.001^{*}$ \\
\hline
\end{tabular}

* Significant at $P \leq 0.05$; Different superscripts represent statistically significantly different groups.

\section{DISCUSSION}

Microorganisms are the major etiological agents responsible for pulpal and periapical pathology ${ }^{1}$. Enterococcus faecalis, facultative, anaerobic, grampositive cocci, has been implicated in persistent root canal infections. It causes up to $90 \%$ of enterococcal endodontic infections ${ }^{1}$. Consequently, the use of root canal filling materials with anti-microbial activity is considered beneficial in an effort to further reduce the number of remaining microorganisms and to eradicate the infection ${ }^{2}$. Ideally, one of the key roles of the sealer is to aggregate the root filling material, 
maintain it as compact mass with no gaps which adheres to the canal walls and provides a single block configuration that seals hermetically the root canal space ${ }^{3}$. This adhesion process involves mechanical forces that yield the intertwining of the material with the dentin structures and may result in a greater sealing ability, thus, reducing the risk of root canal microleakage and maintaining a cohesive filling mass ${ }^{3}$. An antibiotic-enhanced sealer disrupts the microbial environment and maintains bactericidal properties beyond its setting time which is monumental in the outcome of initial endodontic therapy and in preventing re-infection. In this study, the influence of Amoxicillin on sealing ability, adaptation and bond strength of sealers was, thus, evaluated. In zinc oxide and eugenol-based sealers, eugenol is a potent anti-microbial agent and, therefore, it may be attributable to the free eugenol released from the set materials ${ }^{4,5}$. In the present study, the dye extraction method was used for the measurement of apical leakage. The methodology of assessing apical leakage methodology using tooth immersion in various types of dyes, reported for the first time by Grossman in 1939, is perhaps the most widely used ${ }^{6}$. Camps and Pashley ${ }^{7}$ stated that the dye-extraction, or dissolution, technique is promising, rapid and can be performed using equipment that is available in most dental schools. This method recovers all dye that had penetrated the apex. Dye extraction represents an improvement in comparison with the dye penetration technique that underestimates the extent of the dye in the root canal because of simple linear measurements after longitudinal splitting, cross-sectioning or clearing of the specimens ${ }^{7}$. If researchers measure dye penetration on sectioned samples, it is possible that they may misread the largest depth of leakage, thus reaching a wrong conclusion ${ }^{8}$. The linear dye penetration method provides only qualitative results and is not a reliable indicator of clinical success or failure following an endodontic treatment ${ }^{9}$ and is probably less reliable in comparison with the dye extraction technique ${ }^{7}$. The most common tracer used in apical leakage studies is methylene blue in different concentrations ${ }^{10}$. Result of the present study showed that, adding antibiotic to the sealer did not affect the apical leakage. Similar results were found by Gambarini et al ${ }^{11}$ when they tested sealing ability of Kerr PCS and Bioseal (ZnOE with the addition of hydroxyapatite) sealer and found that additive did not adversely affect the sealing property of Bioseal. Also, Shrestha and Mala ${ }^{12}$ showed the same results but Shori et $\mathbf{a l}^{\mathbf{1 3}}$ suggests that addition of triple anti-biotic paste to the sealer increased its sealing ability, reduced the microleakage and also imparted the antimicrobial property to the sealer.

\section{CONCLUSION}

Within the limitations of this study, it could be concluded that adding amoxicillin to zinc oxide and eugenol-based sealer did not affect the sealing ability.

\section{REFERENCES}

1. Kopper MP, Vanni JR, Della Bona A, de Figueiredo JA, Porto S. In vivo evaluation of the sealing ability of two endodontic sealers in root canals exposed to the oral environment for 45 and 90 days. J Appl Oral Sci 2006; 14:43-8.

2. Zhang H, Shen Y, Ruse N D, Haapasalo M. Anti-bacterial activity of endodontic sealers by modified direct contact test against Enterococcus faecalis. J Endod 2009; 35: 51-5.

3. Baroni BJ, Martin T, Mario TF, Erica CN. Bond strength of different endodontic sealers to dentin: push-out test. J Appl Oral Sci 2011; 19:644-7.

4. Stevens RH, Grossman LI. Anti-microbial effect of root canal cementson an obligate anaerobic organism. J Endod 1981; 7:266-7.

5. Hume WR. The pharmacological and toxicological properties of zinc oxide-eugenol. J Am Dent Assoc 1986; 113:789-91

6. Verissimo DM, Do Vale MS. Methodologies for assessment of apical and coronal leakage of endodontic filling materials: a critical view. J Oral Sci 2006; 48:93-8.

7. Camps J, Pashley D. Reliability of the dye penetration studies. J Endod 2003; 29:592-4. 
8. Hosoya N, Nomura M, Yoshikubo A, Arai T, Nakamura J, Cox Charles F. Effect of canal drying method on the apical seal. J Endod 2000; 26:292-4.

9. Kqiku L, Stadtler P, Gruber HJ, Baraba A, Anic L, Miletic L. Active versus passive microleakage of Resilon/ Epiphany and gutta-percha/AH Plus. Aust Endod J 2011; 37:141-6.

10. Taylor JK, Jeansonne BG, Lemon RR. Coronal leakage effects of smear layer, obturation technique, and sealer. J Endod 1997; 23:508-12.

11. Gambarini $\mathrm{G}$, Tagger M. Sealing ability of a new hydroxy- apatite- containing endodontic sealer using lateral condensation and thermatic compaction of gutta-percha, in vitro. J Endod 1996; 22:165-7.

12. Shrestha $S$, Mala K. Evaluation of sealing ability of a root canal sealer with various antibiotic additives: An in vitro study. J Interdiscip Dent 2013;3: 21-4.

13. Shori DD, Shenoi PR, Dhote SP, Makade CS, Gunwal MK, Paralikar AV. To compare and evaluate the sealing ability of root canal sealer with and without triple antibiotic paste using ultraviolet-visible spectrophoto-metric analysis. Int J Prosthodont Restor Dent 2014; 4:48-51. 